\title{
Экономическая история России от Григория Ханина
}

В своей последней монографии ${ }^{1}$ Г. И. Ханин продолжает мучительно искать ответ на вопрос, приписываемый то ли Леху Валенсе, то ли Лешеку Бальцеровичу, а именно: возможно ли в принципе из социалистической ухи восстановить аквариум с рыбками или, другими словами, можно ли зародить жизнь в тоталитарной мертвечине. Правда, таким образом Г.И. Ханин вопрос не ставит. Более того, своими работами он утверждает, что подобные вопросы неуместны, поскольку плановая социалистическая экономика, особенно в ее мобилизационном варианте, была вполне жизнеспособна и даже эффективна. Впрочем, в Польше думали иначе, и у них пока получается.

Начинает свою книгу Г.И. Ханин с анализа институциональных преобразований, что совершенно верно, поскольку долгосрочная экономическая динамика в значительной мере определяется качеством институтов. В этом его последняя книга отличается от предыдущих ${ }^{2}$. Действительно, восемнадцатилетний период, анализируемый в этой книге (а фактически даже больший), вполне подходит под определение долгосрочного. Вместе с тем при анализе институциональных преобразований автор периодически отходит от собственно экономического анализа и вторгается в область политологии, в том числе излишне часто переходит на личности.

Первый тезис, с которого начинается книга, гласит, что в России государство всегда играло активную роль в экономическом развитии. Следует сразу сказать, что государство в любой стране играло и играет ведущую роль, поскольку задает привила поведения всем

${ }^{1}$ Ханин Г.И. Экономическая история России в новейшее время. Т. 4. Экономика Российской Федерации в 1999-2016 годы. М.: Товарищество научных изданий КМК, 2019. 343 c.

${ }^{2}$ Ханин Г.И. Экономическая история России в новейшее время. Т. 1: Экономика СССР в конце 30-х годов - 1987 год. Новосибирск: Издательство НГЕУ, 2008. 516 с.; Ханин Г.И. Экономическая история России в новейшее время. Т. 2: Экономика СССР и РСФСР в 1988-1991 годах. Новосибирск: Издательство НГЕУ, 2010. 408 с.; Ханин Г. И. Экономическая история России в новейшее время. Т. 3: Российская экономика в 1992-1998 годы. Новосибирск: Издательство НГЕУ, 2014. 712 с. (На последнюю работу мною была подготовлена рецензия: Клисторин В. И. «Лихие девяностые» глазами экономиста // ЭКО. 2014. № 10. С. 181-189). 
экономическим субъектам и само является деятельным актором на экономическом поприще.

Данью моде следует объяснить большое внимание со стороны Г.И. Ханина личности В.В. Путина и его роли в институциональных преобразованиях и, главное, в оценке этих преобразований. Это не совсем верно, поскольку важнейшие институциональные реформы, такие как принятие первых двух частей Гражданского кодекса, состоялось в 1994-1995 гг., первая часть Налогового кодекса вступила в силу 01.011999 г., а вторая - с 01.012001 г., Бюджетный кодекс вступил в силу с 01.01.2000 г. Да и налоговая реформа начала XXI века готовилась задолго до того, как А.Л. Кудрин занял пост министра финансов. Бюджетная же реформа, автором которой он, несомненно, был и которая заложила основы гипертрофированной централизации финансовых ресурсов на федеральном уровне, что превратило федеративное строение государства и местное самоуправление в фикцию действительно, во многом его заслуга.

Но об этих важнейших институциональных преобразованиях Г.И. Ханин не пишет. Он обращает внимание на общее направление экономических реформ, связанное с деятельностью Центра стратегических разработок, созданного в декабре 1999 г., и его руководителя Г.О. Грефа. Действительно, так называемая программа Грефа успешно реализовывалась в течение 2-3 лет, но в дальнейшем начался постепенный отход от ее основных положений. Уместно напомнить, что альтернативный программный документ, подготовленный под руководством А.Р. Белоусова и С. Ю. Глазьева, предлагал не столько институциональные преобразования, сколько форсированное наращивание государственных инвестиций. Представляется, что подобная стратегия более импонирует Г.И. Ханину.

Фактический экономический рост он объясняет не столько институциональными преобразованиями в этот период, сколько восстановительным ростом, поддержанным ценами на товары традиционного экспорта, а недостатки развития экономики страны связывает с дефектами кадровой политики.

По непонятным причинам Г.И. Ханин, обсуждая жалкое существование и подчиненное положение таких институтов, как законодательные органы власти, суды, СМИ и политические партии, связывает ситуацию с человеческим фактором, а не целенаправленной политикой высших органов государственной власти. 
Более содержательными представляются разделы первой главы, которые посвящены развитию финансовых институтов. Тут появляются статистические данные, их содержательный анализ и аргументированные выводы. Единственное замечание касается того, что многие элементы рыночной инфраструктуры появились гораздо раньше - в конце 1980-х годов в результате принятия непродуманных нормативных актов, легализовавших частный бизнес в виде кооперативов и совместных предприятий при фактическом отсутствии системы налогообложения и таможенного регулирования и других институтов капитализма. Все это вместе с фактической приватизацией оборотных средств предприятий привело к разбалансировке всей экономики и возникновению так называемого денежного навеса. Это гарантировало инвестиционный и общеэкономический спад, а также гиперинфляцию в последующие годы. Одновременно экспансионистская бюджетная политика в 1990-е годы привела к возникновению финансовых пузырей, банковских кризисов и кризиса неплатежей. Более консервативная бюджетная политика, проводимая с конца 1998 г., привела к оздоровлению сначала государственных, в потом и частных финансов, развитию финансовых институтов на более здоровой основе.

Вторая глава монографии, посвященная развитию отечественного предпринимательства, представляет широкий набор кейсов, которые сами по себе чрезвычайно интересны. Но думается, что на основе этих кейсов трудно сделать обобщения, поскольку они не охватывают такие важные отрасли, как предприятия ОПК, или, например, транспорта и связи. В значительной мере этот недостаток преодолевается в заключительной главе, в которой анализируется динамика развития различных отраслей народного хозяйства. Примечательно, что, описывая развитие крупного капитала в России, Г.И. Ханин избегает столь полюбившегося современной российской публицистике термина «олигархи» и использует его древнеримский аналог «магнаты», более нейтральный в современном русском языке.

Несомненный интерес представляет третья глава «Макроэкономическое развитие», что кажется естественным, поскольку укладывается в традиционную для автора тематику. Более того, эта глава в значительной части является переработкой его предыдущих публикаций, выполненных совместно с Д.А. Фоминым. 
Традиционно макроэкономический анализ начинается с альтернативных оценок динамики основного капитала, что и определяет все последующие расчеты, начиная с динамики ВВП и кончая производительностью труда и эффективности экономики в целом.

Очень информативно в заключении краткое резюме проведенного исследования. Если по ходу знакомства с книгой у читателя и могут возникать вопросы и возражения, то в конце замечательно четко представлены выводы, с которыми практически невозможно аргументированно спорить. Прежде всего, автор напоминает о существовании развилки в будущем развитии страны: продолжении развития институтов рыночной, децентрализованной, капиталистической экономики, или возврат к тому или иному варианту экономики социализма. Он по-прежнему считает, что социалистическая альтернатива возможна и главным аргументом является колоссальный провал в экономическом развитии России за последние 30 лет. Поскольку для него ключевыми критериями экономического процветания или деградации являются накопление основного капитала и рост национального дохода, то такая позиция понятна. Социалистическая индустриализация характеризовалась именно этим, а современная потребительская экономика России - ее полная противоположность.

В этой книге по сравнению с предыдущими томами значительно изменились оценки роли государства и частного сектора. Если ранее Г.И. Ханин неоднократно писал о том, что отечественные предприниматели ничего не предпринимают, скорее, паразитируют на бывшей государственной собственности и занимаются спекуляцией, то теперь, оценивая результаты экономического развития за 20 лет и отмечая, что экономика России не достигла еще уровня развития экономики РСФСР в 1987 г., вину за это он возлагает прежде всего на государство и лишь на $1 / 3$ на частный бизнес (С. 304).

Но проблема создания более справедливого общества, построенного на научной основе и обеспечивающего высокие темпы экономического роста, волнует автора. Поэтому он снабдил свою книгу приложением о возможности возрождения социализма в России. Начинает он с тезиса о том, что в стране растет ностальгия по советским временам. Это действительно так. Далее следует обсуждение сильных сторон и успехов и причин провала социалистического эксперимента. При рассмотрении практи- 
ческих шагов перехода к социализму Г.И. Ханин пишет много верного и действительно необходимого для развития страны, например, о реформе науки и системы образования. Но в целом это выглядит как политическая декларация. Притом внутренне противоречивая. Например, возможно ли в современной экономике воссоздание системы планирования на основе натуральных или натурально-стоимостных балансов и к чему приведет переход к оценке работы предприятий на основе показателя валовой продукции? Представляется, что чувство меры тут автору отказывает. Для обеспечения темпа прироста ВВП в 3\%, по его расчетам, придётся сократить фонд личного потребления в два раза (С. 314). Рассуждения о том, что это можно сделать за счет богатейших слоев населения - чистая фантастика.

Анализируя опыт социалистического строительства в СССР, Г.И. Ханин игнорирует тот факт, что подобные опыты во всех странах приводили к сходным результатам. Дело не в той или иной модели или отдельных ошибках, образовании и лидерских способностях вождей, а в том, что бесконтрольная элита живет по принципу, сформулированному одним из Медичи: «Господь подарил нам этот прекрасный город, так насладимся же этим». Отсюда фантастическое богатство социалистических лидеров, часто не исчисляемое в деньгах, поскольку им принадлежала вся страна. А стремление конвертировать политическую власть в наследуемую собственность - непреодолимо. И, наконец, как писал И. Г. Эренбург в 1922 г.: «В несколько месяцев он познал то, на что Виссарион Александрович Доминантов положил долгие годы, а именно - считать свое дело общим» ${ }^{3}$.

Оригинальная методология и скрупулезная работа с данными - сильные стороны монографии. Любой специалист по экономике России должен иметь все четыре тома «Экономической истории» Г.И. Ханина на своей книжной полке.

КЛИСТОРИН В.И., доктор экономических наук, Институт экономики и организации промышленного производства СО РАН, Новосибирск

3 Эренбург И.Г. Собрание соч. в 6 томах, Т. 1. М.: Художественная литература, 1962. C. 396. 